\title{
HCV Protease Inhibitory, Cytotoxic and Apoptosis-Inducing Effects of Oleanolic Acid Derivatives
}

\author{
Chao-Mei Ma ${ }^{1}$, Xiu-Hong $\mathrm{Wu}^{1,2}$, Hattori Masao ${ }^{1, *}$, Xi-Jun Wang ${ }^{2}$ and Yoshihiro Kano ${ }^{1,3}$ \\ ${ }^{1}$ Institute of Natural Medicine, University of Toyama, 2630 Sugitani, Toyama, Japan. \\ ${ }^{2}$ School of Pharmaceutical Science, Heilongjiang University of Chinese Medicine, China. \\ ${ }^{3}$ Kano Institute of Kampo Medicine, Tokyo, Japan.
}

Received, March 3, 2009, Revised, July 11, 2009, Accepted, August 10, 2009, Published, September 10, 2009.

\begin{abstract}
Purpose. To evaluate oleanolic acid derivatives on liver disease related bioactivities, 29 oleanolic acid derivatives of several series were tested for their inhibitory activity on hepatitis $\mathrm{C}$ viral protease as well as for their cytotoxic and apoptosis-inducing effects on Hep G2 cells. Results. The amino derivatives (17-19) showed potent cytotoxicity. The $\beta$-amino isomer (18) showed strong apoptosis-inducing effect and exhibited more distinct cytotoxicity than the $\alpha$-isomer. The cytotoxicity of hemiesters and hemiamides varied as the chain lengths varied. The oxalic and malonic hemiesters (4 and 5) showed weaker cytototoxicity than oleanolic acid (1), while those with longer chain lengths (6-11) showed higher cytotoxicity. Contrary to the cytotoxic activity, the free amino derivatives (17-19) showed little inhibitory activity on HCV protease. All the hemiesters (4-11) and hemiamides (4-11) showed high activity against $\mathrm{HCV}$ protease. Conclusion. The findings that addition of amino-group enhanced the cytotoxicity and that introduction of acidic group increased the inhibition on $\mathrm{HCV}$ protease may be useful for further design and synthesis of triterpene derivatives as drug candidates for liver diseases.
\end{abstract}

\section{INTRODUCTION}

Oleanolic acid is a pentacyclic triterpene existing widely in the plant kingdom and was reported to have anti-cancer and other interesting bioactivity [1]. This well-known triterpene compound was marketed in China as an oral drug for human liver disorders [2]. Many semi-synthetic derivatives of oleanolic acid were reported to have improved anti-tumor activity [3]. Some oleanolic acid derivatives, such as 2 - cyano $-3,12-$ dioxooleanan - 1, 9 - (11) - dien - 28 - oic acid (CDDO) and CDDO-Me (CDDO-methyl ester) were reported to have entered clinical trials for cancer [4]. The 3-amino derivative of betulinic acid methyl ester and ursolic acid methyl ester were reported to have potent cytotoxicity on tumor cell lines than the parent triterpenes [5, 6], but no reports on the activity of 3-amino derivatives of oleanolic acid were available. Chronic hepatitis $\mathrm{C}$ is the leading cause for several liver diseases including hepatocellular carcinoma. The protease of hepatitis $\mathrm{C}$ virus (HCV) is an essential enzyme for the maturation of the virus and represents one of the attractive therapeutic targets for developing anti-HCV agents [7]. Previously, several series of oleanolic acid derivatives were synthesized in our laboratory and were investigated for their inhibitory activity on HIV protease [8, 9]. These derivatives include oleanolic acid dicarboxylic acid hemiesters or hemiamides, amino derivatives, conjugates of oleanolic acid with AZT or with an alkaloid, FK300. With these compounds in hand, we carried out the present investigation to examine the cytotoxicity and apoptosis-inducing activity on liver cancer cell line Hep G2 and the HCV protease inhibitory activity of 29 oleanolic acid derivatives.

\section{METHODS AND MATERIALS}

\section{Chemistry}

These compounds were synthesized and their structures were confirmed as described in the previous papers $[8,9]$.

Corresponding Authors: Hattori Masao, Institute of Natural Medicine, University of Toyama, 2630 Sugitani, Toyama 930-0194, Japan. Email: saibo421@inm.u-toyama.ac.jp 
All the compounds were pure compounds except for 19 which is a mixture of two isomers, $\alpha$ - and $\beta$ forms in a ratio of 1:5.

\section{Cytotoxicity Assay}

Hep G2 cells (lot number: 07112007) were purchased from Health Science Research Resources Bank, Osaka, Japan.

Growth inhibitory effect on Hep G2 of the oleanolic acid derivatives was determined by a 3 ( 4,5-dimethylthiazol - 2-yl )-2,5-diphenyl tetrazolium bromide (MTT) method on 96-well plates.

\section{Apoptosis Detection Assay}

The apoptosis assay was carried out using an annexin V-FITC apoptosis detection kit (BioVision, Mountain View, CA 94043 USA) following the protocol provided by the manufacturer. The early apoptosis was assessed by evaluation of phosphatidylserine (PS) residues on the cell surface with annexin $\mathrm{V}$ staining. Late stage apoptosis when the cells have lost membrane integrity was measured by propidium iodide (PI) staining. Hep G cells $\left(3 \times 10^{5}\right)$ were seeded in 96 -well plates and the next day, were treated with $100 \mu \mathrm{g} / \mathrm{ml}$ of oleanolic acid (1) or $10 \mu \mathrm{g} / \mathrm{ml}$ of 7 or 18. After being incubated for further 48 hours in a $5 \% \mathrm{CO}_{2}$ incubator, the cells were stained with Annexin V and propidium iodide using the Annexin V-FITC apoptosis detection kit I (BD Pharmingen, SanDiego, CA92121, Lot\# 89200). Cells were collected and analyzed by a flow cytometry (FACSCalibur, Becton, Dickinson). Annexin VFITC binding was determined at $\mathrm{Ex}=488 \mathrm{~nm}$ and $\mathrm{Em}=530 \mathrm{~nm}$ using an FITC signal detector (FL1). PI staining was determined at $\mathrm{Ex}=488 \mathrm{~nm}$ and $\mathrm{Em}=585 \mathrm{~nm}$ by a PE emission signal detector (FL2).

\section{HCV Protease Assay}

$\mathrm{HCV}$ NS3/4A protease (lot\# 046-079) and SensoLyte $^{\mathrm{TM}} 520 \mathrm{HCV}$ Protease Assay Kit *Fluorimetric* (lot\# AK 71145-1018) were purchased from AnaSpec, San Jose, CA, USA. The substrate was a 5-FAM/QXL ${ }^{\text {TM} 520 ~ F R E T ~ p e p t i d e ~}$ based on the sequence of Ac - Asp - Glu - Asp (EDANS) - Glu - Glu - Abu - $\psi-[\mathrm{COO}] \mathrm{Ala}-$
Ser - Lys (DABCYL) - $\mathrm{NH}_{2}$. Fluorescence was measured by TECAN GENios plate reader at excitation/emission $485 / 530 \mathrm{~nm}$. The assay was carried out on BD Falcon ${ }^{\mathrm{TM}}$ Microtest ${ }^{\mathrm{TM}}$ 384-well $120 \mu \mathrm{l}$ black assay plates (lot\#05391155) following the procedure described in a previous paper with DMSO as solvent for all compounds [10].

\section{RESULTS}

\section{Cytotoxicity}

The cytoxicity of the triterpene derivatives was evaluated by MTT method. These compounds inhibited the growth of Hep G2 cells in concentration-dependent manner. The $\mathrm{EC}_{50}$ values of these triterpenes against Hep G2 were listed in Table 1 represented as the concentrations that inhibited $50 \%$ of the Hep G2 cell growth when compared with a control containing no triterpene compounds.

Oleanolic acid (1), its methyl ester (2) and its acetate (3) showed appreciable cytotoxicity on the tumor cell line.

Of the dicarboxylic acid hemiesters (4-11), an interesting phenomenon was observed that the two compounds (4 and 5) with relatively short carbon chains showed much weaker cytotoxicity than oleanolic acid. However, as the chain length increased (6-11), the cytotoxicity increased sharply. Compounds 6-10 with chain lengths of 4-8 carbons showed strong cytotoxicity on the cancer cell line with $\mathrm{IC}_{50}<10 \mu \mathrm{g} / \mathrm{ml}$. Compound 8 with two methyl side chains exhibited similar cytotoxicity as the compound (7) with straight chain did. Methylation of the 28-carboxyl group of these compounds slightly increased the cytotoxicity (compounds 12, 13 v.s. 8, 9). Though the cytotoxicity was significantly increased by introducing a 6-carbon chain at position 3 (9 v.s. 1$)$, the addition of a similar chain at position 28 had little effect on the cytotoxicity (14 v.s. 1).

The hydroxyimino compounds $(\mathbf{1 5}, \mathbf{1 6})$ and the 3-amino compounds $(\mathbf{1 7}, \mathbf{1 8})$ showed increased cytotoxicity when compared with the parent compound (1). Like that observed on the cytotoxicity of ursolic acid derivatives [6], the most potent compound on the cytotoxicity assay was the 3- $\beta$-amino derivative (18). 
Table 1. Cytotoxicity on Hep G2 cells and HCV protease inhibition of oleanolic acid derivatives
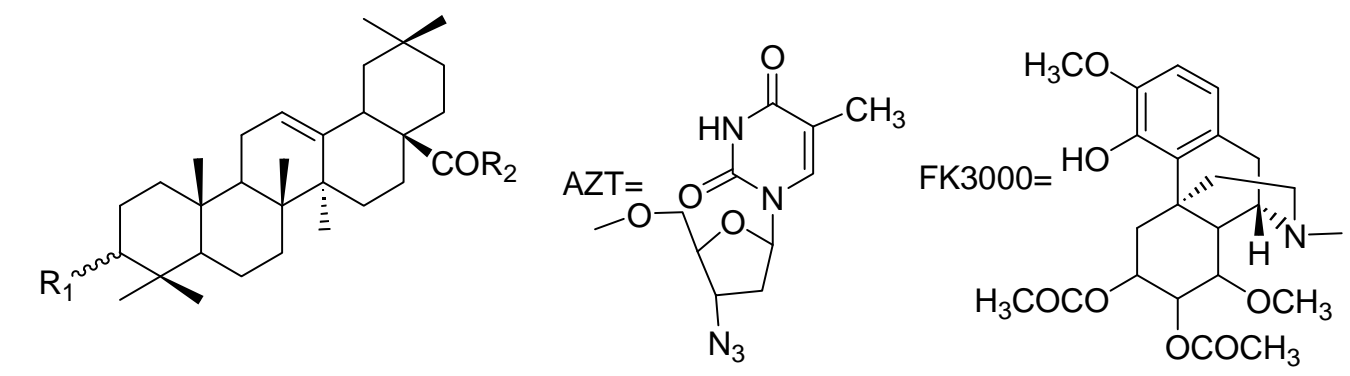

\begin{tabular}{|c|c|c|c|c|}
\hline N0. & $\mathrm{R}_{1}$ & $\mathrm{R}_{2}$ & $\mathrm{EC}_{50}$ & $\mathrm{IC}_{50}$ \\
\hline 1 & $\beta-\mathrm{OH}$ & $\mathrm{OH}$ & $84.1 \pm 3.1$ & $26 \pm 3.9$ \\
\hline 2 & $\beta-\mathrm{OH}$ & $\mathrm{OCH}_{3}$ & $25.0 \pm 3.6$ & $>100 \pm 13.3$ \\
\hline 3 & $\beta-\mathrm{OCOCH}_{3}$ & $\mathrm{OH}$ & $31.2 \pm 6.4$ & $35 \pm 5.4$ \\
\hline 4 & $\beta-\mathrm{OCOCOOH}$ & $\mathrm{OH}$ & $>100 \pm 2.0$ & $9 \pm 5.1$ \\
\hline 5 & $\beta-\mathrm{OCOCH}_{2} \mathrm{COOH}$ & $\mathrm{OH}$ & $>100 \pm 2.0$ & $9 \pm 3.9$ \\
\hline 6 & $\beta-\mathrm{OCO}\left(\mathrm{CH}_{2}\right)_{2} \mathrm{COOH}$ & $\mathrm{OH}$ & $5.6 \pm 2.7$ & $13 \pm 6.5$ \\
\hline 7 & $\beta-\mathrm{OCO}\left(\mathrm{CH}_{2}\right)_{3} \mathrm{COOH}$ & $\mathrm{OH}$ & $4.5 \pm 3.2$ & $14 \pm 6.1$ \\
\hline 8 & $\beta-\mathrm{OCOCH}_{2} \mathrm{C}\left(\mathrm{CH}_{3}\right)_{2} \mathrm{CH}_{2} \mathrm{COOH}$ & $\mathrm{OH}$ & $6.4 \pm 2.8$ & $10 \pm 4.0$ \\
\hline 9 & $\beta-\mathrm{OCO}\left(\mathrm{CH}_{2}\right)_{4} \mathrm{COOH}$ & $\mathrm{OH}$ & $8.3 \pm 4.5$ & $13 \pm 4.8$ \\
\hline 10 & $\beta-\mathrm{OCO}\left(\mathrm{CH}_{2}\right)_{6} \mathrm{COOH}$ & $\mathrm{OH}$ & $8.7 \pm 1.4$ & $11 \pm 2.6$ \\
\hline 11 & $\beta-\mathrm{OCO}\left(\mathrm{CH}_{2}\right)_{8} \mathrm{COOH}$ & $\mathrm{OH}$ & $16.2 \pm 3.5$ & $12 \pm 5.7$ \\
\hline 12 & $\beta-\mathrm{OCOCH}_{2} \mathrm{C}\left(\mathrm{CH}_{3}\right)_{2} \mathrm{CH}_{2} \mathrm{COOH}$ & $\mathrm{OCH}_{3}$ & $3.5 \pm 4.5$ & $7 \pm 3.8$ \\
\hline 13 & $\beta-\mathrm{OCO}\left(\mathrm{CH}_{2}\right)_{4} \mathrm{COOH}$ & $\mathrm{OCH}_{3}$ & $5.4 \pm 3.6$ & $27 \pm 6.1$ \\
\hline 14 & $\beta-\mathrm{OH}$ & $\mathrm{NH}\left(\mathrm{CH}_{2}\right)_{5} \mathrm{COOH}$ & $87.5 \pm 3.1$ & $64 \pm 6.1$ \\
\hline 15 & $=\mathrm{NOH}$ & $\mathrm{OCH}_{3}$ & $6.0 \pm 1.9$ & $>100 \pm 6.1$ \\
\hline 16 & $=\mathrm{NOH}$ & $\mathrm{OH}$ & $3.1 \pm 2.2$ & $35 \pm 11.3$ \\
\hline 17 & $\alpha-\mathrm{NH}_{2}$ & $\mathrm{OCH}_{3}$ & $10.3 \pm 2.3$ & $>100 \pm 4.4$ \\
\hline 18 & $\beta-\mathrm{NH}_{2}$ & $\mathrm{OCH}_{3}$ & $1.9 \pm 1.6$ & $85 \pm 10.8$ \\
\hline 19 & $\alpha-\mathrm{NH}_{2}+\beta-\mathrm{NH}_{2}$ & $\mathrm{OH}$ & $4.9 \pm 4.6$ & $68 \pm 2.1$ \\
\hline 20 & $\alpha-\mathrm{NHCO}\left(\mathrm{CH}_{2}\right)_{4} \mathrm{COOH}$ & $\mathrm{OCH}_{3}$ & $87.4 \pm 4.0$ & $21 \pm 7.5$ \\
\hline 21 & $\beta-\mathrm{NHCO}\left(\mathrm{CH}_{2}\right)_{4} \mathrm{COOH}$ & $\mathrm{OCH}_{3}$ & $14.9 \pm 3.6$ & $7 \pm 6.2$ \\
\hline 22 & $\alpha-\mathrm{NHCO}\left(\mathrm{CH}_{2}\right)_{4} \mathrm{COOH}$ & $\mathrm{OH}$ & $>100 \pm 5.3$ & $20 \pm 5.7$ \\
\hline 23 & $\beta-\mathrm{NHCO}\left(\mathrm{CH}_{2}\right)_{4} \mathrm{COOH}$ & $\mathrm{OH}$ & $>100 \pm 3.4$ & $8 \pm 2.8$ \\
\hline 24 & $\beta$-NHCO $\left(\mathrm{CH}_{2}\right)_{4}$ COoleanolic acid & $\mathrm{OH}$ & $>100 \pm 1.2$ & $3 \pm 4.9$ \\
\hline 25 & $\alpha-\mathrm{NHCO}\left(\mathrm{CH}_{2}\right)_{4} \mathrm{COOFK} 3000$ & $\mathrm{OCH}_{3}$ & $>100 \pm 1.8$ & $>100 \pm 7.2$ \\
\hline 26 & $\beta-\mathrm{NHCO}\left(\mathrm{CH}_{2}\right)_{4} \mathrm{COOFK} 3000$ & $\mathrm{OCH}_{3}$ & $>100 \pm 2.6$ & $75 \pm 8.9$ \\
\hline 27 & $\alpha-\mathrm{NHCO}\left(\mathrm{CH}_{2}\right)_{4} \mathrm{COOazt}$ & $\mathrm{OCH}_{3}$ & $>100 \pm 4.3$ & $54 \pm 9.3$ \\
\hline 28 & $\beta-\mathrm{NHCO}\left(\mathrm{CH}_{2}\right)_{4} \mathrm{COOazt}$ & $\mathrm{OCH}_{3}$ & $>100 \pm 1.7$ & $39 \pm 5.4$ \\
\hline 29 & $\beta-\mathrm{OCO}\left(\mathrm{CH}_{2}\right)_{4} \mathrm{COOazt}$ & $\mathrm{OH}$ & $>100 \pm 3.9$ & $8 \pm 6.8$ \\
\hline
\end{tabular}

$\mathrm{EC}_{50}$ : Concentrations that inhibited $50 \%$ of the growth of the tumor cell line. The results were expressed as $\mu \mathrm{g} / \mathrm{ml} \pm \mathrm{RSD} \%(\mathrm{n}=3)$. $\mathrm{IC}_{50}$ : Concentrations that inhibited $50 \%$ of $\mathrm{HCV}$ protease activity. The results were expressed as $\mu \mathrm{g} / \mathrm{ml} \pm \mathrm{RSD} \%(\mathrm{n}=3)$. 
AZT, a nucleoside analog was originally designed to treat cancer and was the first approved drug for the treatment of AIDS through the mechanism of inhibiting reverse transcriptase [11]. FK3000 is a morphinan type alkaloid reported to have anti-herpes simplex virus activity in vitro and in vivo [12]. Though oleanolic acid (1) itself showed appreciable cytotoxicity on the tumor cell line, neither its FK3000 conjugates (25-26) nor the AZT conjugates (27-29) showed cytotoxicity at a concentration as high as $100 \mu \mathrm{g} / \mathrm{ml}$.

\section{Apoptosis}

As oleanolic acid (1) and some of its derivatives were reported to induce apoptosis in human cancer cells $[4,13]$, we tested the present compounds for their effects on annexin V-FITC binding and PI staining of Hep G2 cells. We compared the annexin V-FITC binding and PI staining results of Hep G2 cells treated with oleanolic acid (1) or $\mathbf{7}$ or $\mathbf{1 8}$ by flow cytometric analysis. As shown in Figure 1 and Table 2, cells treated with $10 \mu \mathrm{g} / \mathrm{ml}$ of $\mathbf{7}$ or $\mathbf{1 8}$ showed significant increase in apoptosis compared with those treated with a higher concentration (100 $\mu \mathrm{g} / \mathrm{ml}$ ) of oleanolic acid (1). Especially for $\mathbf{1 8}$ treated cells, when compared with $\mathbf{1}$ treated cells, both the early apoptosis (Annexin V staining, $17.21 \%$ v.s. $1.53 \%$ of total in the LR for $\mathbf{1 8}$ and $\mathbf{1}$, respectively) and the late stage apoptosis when the cells have lost membrane integrity [propidium iodide (PI) staining] were significantly increased.

\section{HCV Protease Inhibition}

As shown in Table 1, all the dicarboxylic acid hemisters (4-11) and hemiamides (20-23) of oleanolic acid showed better inhibitory activity on HCV protease than oleanolic acid (1) itself, while the derivatives with a free amino group (17-19) showed much weaker activity on the protease. The oleanolic acid-AZT conjugates showed inhibition on $\mathrm{HCV}$ protease too. The most potent $\mathrm{HCV}$ protease inhibitory activity was observed on a dimeric compound (24).

Table 2. Quadrant statistics of Hep G2 cells treated with compounds $1(100 \mu \mathrm{g} / \mathrm{ml}), 7$ (10 $\mu \mathrm{g} / \mathrm{ml})$ or $\mathbf{1 8}(10 \mu \mathrm{g} / \mathrm{ml})$ analyzed by flow cytometry.

\begin{tabular}{cccccccccc}
\hline Quad & \multicolumn{3}{c}{ Events } & \multicolumn{3}{c}{ \% Gate } & \multicolumn{3}{c}{ \% Total } \\
\hline & $\mathbf{1}$ & $\mathbf{7}$ & $\mathbf{1 8}$ & $\mathbf{1}$ & $\mathbf{7}$ & $\mathbf{1 8}$ & $\mathbf{1}$ & $\mathbf{7}$ & $\mathbf{1 8}$ \\
UL & 47 & 240 & 248 & 0.84 & 4.22 & 3.94 & 0.47 & 2.40 & 2.48 \\
UR & 342 & 1151 & 1421 & 6.10 & 20.23 & 22.56 & 3.42 & 11.51 & 14.21 \\
LL & 5064 & 4170 & 2909 & 90.33 & 73.29 & 46.18 & 50.64 & 41.70 & 29.09 \\
LR & 153 & 129 & 1721 & 2.73 & 2.27 & 27.32 & 1.53 & 1.29 & 17.21 \\
\hline
\end{tabular}
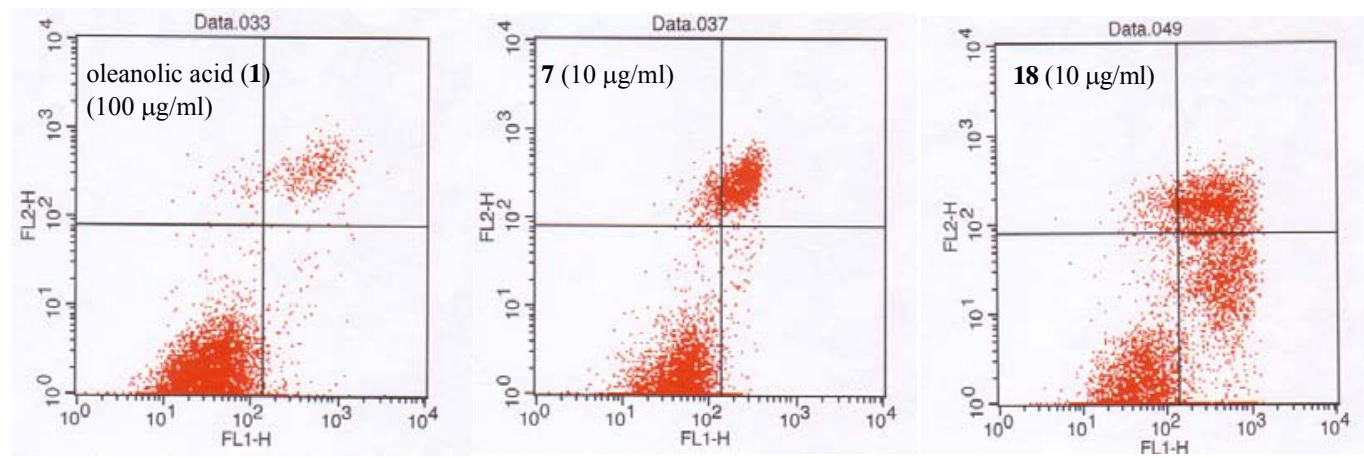

Figure 1. Flow cytometry analysis of $\mathbf{1 ,} \mathbf{7}$ or $\mathbf{1 8}$ treated Hep G2 cells stained with Annexin V (FL1) and propidium iodide (FL2). 


\section{DISCUSSION}

According to the world cancer report 2008, cancer has become one of the most devastating diseases worldwide and in most countries there is hardly a family without a cancer victim [14]. Liver cancer is among the most common malignancies worldwide and is the second deadly cancer only next to pancreatic cancer. The five-year relative survival rate for liver cancer is less than $10 \%$ for all races from 1995-2001 [15]. On the other hand, about $3 \%$ of the global population is infected with $\mathrm{HCV}$ and the chronic infection of this virus is the leading cause of cirrhosis, hepatocellular carcinoma and liver transplantation in developed countries [7]. It is urgently needed to develop new agents against liver cancer and hepatitis $\mathrm{C}$ infection. Oleanolic acid is a well known triterpene existing widely in plant kingdom. The rich nature resource of oleanolic acid is warrant for using this compound as starting material to synthesize more bioactive derivatives. The present results indicated that the 3-amino-oleanolic acids have high cytotoxicity on Hep G2 cells. The mechanism of action may at least partially due to the ability of the compound to induce apoptosis of the cancer cells. Similar compounds, 3-amino-ursolic acids [6] and 3-amino-betulinic acid [5] have been reported to highly cytotoxic to other cancer cell lines. These results indicated that addition of amino-group(s) to triterpene skeletons may be an effective way to enhance the anti-tumor activity of triterpenes and it is worthwhile to do further research to evaluate the in vivo anti-tumor activity and the toxicity of these triterpene derivatives. The significant difference in the cytotoxicity of the dicarboxilic acid hemiesters suggested that besides acidity, other factors, such as chain length or lipophilicities also play important roles on the cytotoxicity. A dimeric compound (24) and all the dicarboxylic acid hemisters (4-11) and hemiamides (20-23) of oleanolic acid investigated in this study showed impressive inhibition on HCV protease. These data provided information for understanding the structure-activity relationships of oleanolic acid derivatives on Hep G2 cancer cells and on inhibition of HCV protease. The present results together with data from other literatures may be used to design and synthesis of lead compounds for the development of new type of anti-cancer and anti-HCV agents.

\section{REFERENCES}

1. Sultana N, Ata A. Oleanolic acid and related derivatives as medicinally important compounds. J. Enzyme. Inhib. Med. Chem. 2008; 23: 739-756.

2. Liu J. Pharmacology of oleanolic acid and ursolic acid, J. Ethnopharmacol. 1995; 49: 57-68.

3. Honda T, Gribble GW, Suh N, Finlay HJ, Rounds BV, Bore L, Favaloro Jr FG, Wang Y, Sporn MB. Novel synthetic oleanane and ursane triterpenoids with various enone functionalities in ring a as inhibitors of nitric oxide production in mouse macrophages. J. Med. Chem. 2000; 43: 1866-1877.

4. Hyer ML, Shi R, Krajewska M, Meyer C, Lebedeva IV, Fisher PB, Reed JC. Apoptotic activity and mechanism of 2-cyano-3,12-dioxoolean-1,9-dien28-oic - acid and related synthetic triterpenoids in prostate cancer. Cancer Res. 2008; 68, 2927-2933.

5. Kim DSHL, Pezzuto JM, Pisha E. Synthesis of betulinic acid derivatives with activity against human melanoma. Bioorg. Med. Chem. Lett. 1998; 8: 1707-1712.

6. Ma CM, Cai SQ, Cui JR, Wang RQ, Tu PF, Hattori M, Daneshtalab M. The cytotoxic activity of ursolic acid derivatives. Eur. J. Med. Chem. 2005; 40: 582-589.

7. Stauber RE, Stadlbauer V. Novel approaches for therapy of chronic hepatitis C. J. Clin. Virol. 2006; 36:87-94.

8. Ma CM, Nakamura N, Mattori M, Chemical modification of oleanene type triterpenes and their inhibitory activity against HIV-1 protease dimerization. Chem. Pharm. Bull. 2000; 48: 1681-1688.

9. Ma CM, Nakamura N, Hattori M, Kawahata T, Otake T. Inhibitory effects of triterpene-azidothymidine conjugates on proliferation of human immunodeficiency virus type 1 and its protease. Chem. Pharm. Bull. 2002; 50: 877-880.

10. Phuong DT, Ma CM, Hattori M, Jin JS. Inhibitory effects of antrodins A-E from Antrodia cinnamomea and their metabolites on hepatitis $\mathrm{C}$ virus protease. Phytother. Res. 2009; 23: 582-584.

11. http://en.wikipedia.org/wiki/Zidovudine, access date, 
Feb. 28, 2009.

12. Nawawi A, Ma CM, Nakamura N, Hattori M, Kurokawa M, Shiraki K, Kashiwaba N, Ono M. Anti-herpes simplex virus activity of alkaloids isolated from Stephania cepharantha. Biol. Pharm. Bull. 1999; 22: 268-274.

13. Zhang PX, Li HM, Chen D, Ni JH, Kang YM, Wang SQ. Oleanolic acid induces apoptosis in human leukemia cells through caspase activation and
poly(ADP-ribose) polymerase cleavage. Acta Biochim. Biophys. Sinica. 2007; 39: 803-809.

14. http://apps.who.int/bookorders/anglais/detart1.jsp?se sslan $=1 \& \operatorname{codlan}=1 \& \operatorname{cod} c o l=76 \& \operatorname{codcch}=16$. Access date: Aug. 16, 2009.

15. (http://intl-caonline.amcancersoc.org/cgi/content/ful 1/56/2/106. Access date: Aug. 17, 2009. 